\title{
Continuants, identity and essentialism
}

\author{
Nicholas Unwin ${ }^{1}$ \\ Received: 24 July 2017 / Accepted: 23 July 2018 / Published online: 30 July 2018 \\ (c) The Author(s) 2018
}

\begin{abstract}
The question of whether it is permissible to quantify into a modal context is reexamined from an empiricist perspective. Following Wiggins, it is argued that an ontology of continuants implies essentialism, but it is also argued, against Wiggins, that the only conception of necessity that we need to start out with is that of analyticity. Essentialism, of a limited kind, can then be actually generated from this. An exceptionally fine-grained identity criterion for continuants is defended in this context. The debate between Wiggins and Ayer over the legitimacy of de re modality is then examined in the light of these results, and it is argued that my position is consistent with Ayer's minimalist assumptions. It is also argued that non-continuants will not sustain the essential/accidental distinction, thus giving some concessions to the sceptics. It is also shown that there are close connections between these issues and the more modern two-dimensionalist way of disentangling the necessary from the a posteriori, and that the latter needs to learn from the former.
\end{abstract}

Keywords Continuant $\cdot$ Identity $\cdot$ Essentialism $\cdot$ de re modality $\cdot$ Sortal $\cdot$ David Wiggins · A.J. Ayer

\section{Introduction}

One of the more significant developments in philosophy in the last half century or so has been the widespread rejection of the Kantian thesis that necessity is a mark of the a priori. Instead, following work by Kripke (1980), Putnam (1975) and others, it is now generally accepted that there can be necessary a posteriori truths. Related to this has been the rise of quantified modal logic (QML), in particular the legitimation of quantifying into modal contexts, what Quine (1976) calls the 'third grade of modal involvement'. The epistemological implications of these developments are, however, uncertain. Ayer (1979), for example, claims that there is nothing more to necessity

\footnotetext{
Nicholas Unwin

n.unwin@lancaster.ac.uk

1 Lancaster University, Lancaster, UK
} 
than analyticity, and therefore that all necessary truths are a priori after all. Thus QML has to be ruled out of bounds, since 'It is analytic that __ yields an opaque context (i.e. one which does not license the substitution within it of co-referring terms salva veritate), so one cannot quantify into it. ${ }^{1}$ Such a hard line view seems to be a consequence of an austere empiricism that descends from Hume, but comparatively few people nowadays agree with Ayer on this point. However, it remains unclear how QML is to be rendered consistent with empiricism of any kind, if only because it is unclear how the senses can detect what goes on in other possible worlds. ${ }^{2}$ It follows that the question of how necessary a posteriori knowledge is possible is one which urgently needs to be answered.

In this paper, I shall show how a limited class of necessary a posteriori truths can be understood and known about even from within Ayer's austere conception of necessity. This class concerns the essential properties of ordinary spatiotemporal continuants, such as human beings, horses, trees and ships. Following Wiggins (1980, 2001), a sortal-based theory of the individuation of continuants is defended, but of an unusually radical kind. It is then shown how a limited type of essentialism, albeit of a rather oldfashioned variety, can actually be generated from this framework, an essentialism which sustains the necessary a posteriori, but which needs far fewer assumptions than Wiggins himself requires.

\section{Some modal logical issues}

It might be thought that there really is no problem here, or that if there is, it is a seriously dated one. ${ }^{3}$ But although it is true that the discussion has moved on considerably since the late 1970s, there are earlier and more fundamental issues which have not been properly resolved and which still require attention. Likewise, some might say that, in a post-Kripkean age, the real question should be not 'How can there be necessary a posteriori truths?', but rather 'Why on earth did we ever think that necessary truths had to be a priori in the first place?' The necessary/contingent distinction is metaphysical, whereas the a priori/a posteriori distinction is epistemological, and so it might seem - and usually does nowadays - that we are dealing with quite different topics. Yet the situation is not so straightforward, and for several reasons. Firstly, the original suspicion that we cannot know non-trivial necessary truths to be true remains real. Secondly, the fundamental status of QML rests on some very basic, usually undiscussed assumptions that need to be investigated. I shall attempt to show that some of these assumptions can in fact be justified, but that real work needs to be done in order to establish this.

\footnotetext{
1 Thus consider what ' $\exists x$ (it is analytic that Hesperus $=x$ )' is supposed to mean. Unless we read the quantifier substitutionally (which brings in problems of its own), we are stymied by the fact that 'Hesperus = Hesperus' is analytic, but 'Hesperus $=$ Phosphorus' is not.

2 The word 'empiricism' is open to many definitions. What is crucial for present purposes is that the doctrine include commitment to the thesis that a priori knowledge does not extend beyond that which can be obtained by conceptual analysis, and that necessity is ultimately reducible to analyticity.

3 See the preface to Williamson (2013), for example.
} 
It may, again, be protested that such work is unnecessary, since the more recent development of two-dimensional semantics, for example, has shown us how to disentangle the necessary and the a posteriori, and this is where the debate has now largely shifted. ${ }^{4}$ Yet the specific issue of continuants and their identity criteria through time does not emerge as crucial in this development, and this, I shall argue in Sect. 3, reveals a serious limitation. The essential/accidental distinction does not work well with entities other than continuants, as we shall see in Sect. 5, and the two-dimensionalist approach does not address these ontological issues. Something is therefore missing in the modern account which the earlier Wiggins-Ayer debate addressed directly. Hence the continued relevance of the latter.

Still, some might say that it is obvious that we have a serviceable conception of necessity which enables us to quantify into modal contexts: the simple existence of QML is enough to prove that. But this is wrong. Undeniably, QML is a very nice, internally coherent piece of pure mathematics, but that does not prove that it has any application. Quine's wholly negative position, for example, is hardly refuted by the mere mathematical existence of QML.

An appeal to ordinary language, notably the fact that there are many de re locutions in English which have a natural, intuitive meaning, is also inconclusive. After all, intuitively, we may quantify into many contexts that are definitely opaque, such as belief-contexts. As Quine (1971: p. 102) himself points out, the sentence 'Ralph believes that someone is a spy' can be read either 'notionally' (de dicto), as

Ralph believes that $\exists x$ ( $x$ is a spy)

(i.e. 'Ralph believes that there are spies', probably true)

or 'relationally' (de re) as

$\exists x$ (Ralph believes that $x$ is a spy)

(i.e. 'There is a specific individual whom Ralph believes to be a spy', probably false).

The difference is certainly intuitive. But as Quine goes on to argue, the latter reading of the sentence does not survive close scrutiny. Perhaps he is wrong here, but at any rate we cannot argue that belief-contexts are potentially transparent just because sentences, so construed, appear in ordinary language. At the very least, further justification is needed. Likewise, we cannot 'prove' that belief-contexts are transparent by inventing quantified doxastic logic, something formally parallel to QML. We need to demonstrate that belief-contexts genuinely satisfy the principles of this logic; and the same is true of ordinary modal contexts.

It may be protested that QML is not uninterpreted since it has semantics as well as proof theory (and a plethora of soundness and completeness theorems, and so forth). But possible world semantics (i.e. Kripke semantics) is also just a piece of uninterpreted pure mathematics unless and until the 'possible' in 'possible world' is appropriately explicated. And once again, belief-contexts could de facto be assigned this kind of formal semantics, but without any legitimate application. Kripke's own strategy, namely to appeal to an intuitive notion of rigid designation, does not help

${ }^{4}$ See Garcia-Carpintero and Macia (2006), for example. 
either. We cannot talk intelligibly about trans-world identity until we have already established that the modal operator is transparent. ${ }^{5}$

Alternatively, we could follow Wiggins (1979) and treat the modal operator not as a sentential operator but as a predicate modifier 'NEC', whose logic is then carefully explicated. The syntax of such a system guarantees that contexts are extensional and transparent. Yet this is also an inconclusive procedure, and for a similar reason. We could equally stipulate a doxastic predicate modifier 'Believed-by-Ralph-to-be', but this does not prove that doxastic contexts are really extensional, or are capable of being read as such. Again, it may be that we just have an uninterpretable piece of pure mathematics, or at least one which cannot be interpreted in the way intended.

That the modal operator has to give rise to an extensional context if it is to work as required is assumed in the famous theorem that all true identity statements are necessarily true. Indeed, the standard Barcan proof of this principle is really little more than a trivial application of Leibniz's law. The crucial assumption in the subargument (which forms the crux of the proof)
(1) $x=y \quad$ Premise
(2) $\square(x=x)$ Theorem
(3) $\square(x=y) \quad 1,2$ Identity Elimination rule

is not listed at all: it is that ' $\square$ ' is transparent and therefore licenses the substitution of identicals salva veritate. This is never proved but is simply assumed at the outset, and the blatant falsity of this principle when ' $\square$ ' is read as 'It is analytic that __' or as 'Ralph believes that___ shows that a huge amount of philosophy needs to be done before QML even gets started. ${ }^{6}$

Again, it may be protested that all this is old hat, and that more recent developments have managed to establish the legitimacy of QML. But this should be disputed. The underlying assumptions may be taken for granted nowadays, but the issue of whether and precisely where QML and the doctrine of essentialism have legitimate application should remain live. In this paper, I shall show how an ontology of continuants permits these things even given very minimal empiricist assumptions; whereas attempts to apply such things to other ontologies, notably four-dimensional processes, is far less satisfactory. There is therefore a lot more going on behind the scenes than is often acknowledged.

\section{Continuants and sortals}

Continuants or substances (i.e. ordinary physical objects and persons) are distinguished from occurrents or processes by the fact that they have no temporal parts. ${ }^{7}$ They are

\footnotetext{
5 Suppose (actually existing) $a$ can be reidentified in a possible world $w$ where it has property $F$ (it is surely extraordinary for anything without properties to exist in any world). Then ' $\exists x \triangleright F x$ ' is true in our world, and involves quantifying into a modal context. Contrapositively, if we can never quantify into a modal context, then we cannot talk of trans-world identity.

${ }^{6}$ For a robust defence of contingent identity, see Yablo (1987). However, Yablo rejects the possibility of having two objects occupying the same places at the same times, contrary to the position argued for here.

7 There are many controversies here, of course. See, for example, Della Rocca (2011), Hawley (2015), Merricks (1995), and Simons (2000), to give a small sample of a huge literature.
} 
three-dimensional entities which persist through time, but completely and wholly exist at every time at which they exist at all. For example, if I hold a continuant such as a butterfly in my hands, then I hold all of it, even if I do not always hold it. By contrast, if I observe a process, such as a football match, for only a part of the time during which it takes place, then I observe only part of the process. Processes are four-dimensional entities with temporal as well as spatial parts. Continuants can be reidentified at different times, and they are genuinely identical, not just (different) parts of a temporally extended entity; and this means that they need solid identity criteria. Given our completely existing entity X observed at time $t$, we must work out where and what $\mathrm{X}$ is at $t^{\prime}$, assuming that $\mathrm{X}$ continues to exist then.

Spatiotemporal continuity might be thought to yield a necessary condition for identity: for a given man A (for example) to be the same man as one later identified as B, one must be able to trace a spatiotemporally continuous path from A to B. Wiggins, however, insists that bare continuity is insufficient to yield identity criteria. ${ }^{8}$ His reasoning is complex, but the general idea is quite simple. It is possible (my example, not Wiggins's) to trace a spatiotemporal route from one man to a completely different one: firstly we have a continuant which occupies exactly the same space as me; then this creature ingests air and excretes human tissue whilst retaining the outline shape of a man; then it is a migrating man-shaped portion of air (the shape migrates, not the air); then it ingests some of your tissue whilst continuing to excrete air; and finally it absorbs you altogether. Here we have a continuant with a somewhat idiosyncratic metabolism which is spatiotemporally continuous linking me to you: but it does not follow that I am you. How can we block such false identifications? Wiggins's answer is that we must focus not on physical objects in general, but rather on objects of a particular sort. I am not just a continuant; I am specifically a man. Moreover, what sustains my identity through time is that there is a spatiotemporally continuous man linking me at different times. A man-shaped portion of air, by contrast, cannot constitute a man, and this delegitimizes the false identification. It does not rule out the unusual continuant as such, for we could perhaps introduce a new sortal noun for entities of that type; but it ensures that such entities, whatever they are, are not men. This is why we must introduce sortal properties into the discussion. ${ }^{9}$

But a further refinement is needed. If I undergo gender reassignment, and then change my mind and undergo it again, I shall certainly be the same man as I was before. I cannot hope to escape punishment for a crime, for example, by undergoing a plurality of gender reassignments. However, there is no longer a spatiotemporally continuous man linking me up, though there is a spatiotemporally continuous human being. This ensures that we need to focus on sortals of the latter kind, not the former. Let us call them 'pure sortals' [Wiggins (1980: p. 24) calls them 'substance concepts']. Human being is thus a pure sortal, whereas man (human-who-is-male), musician (human-whois-musical), child (human-who-is-biologically-immature), more generally $\varphi$-human (human-who-is- $\varphi$ ), and so on, are, by contrast, impure (or restricted) sortals. The latter do not merely give us what Aristotle called predications in the category of substance

\footnotetext{
8 '... nothing is to made of bare continuity. A fortiori, neither identity, nor even the identity relation as restricted to material objects, is the same relation as continuity' (Wiggins 1980: p. v).

9 For more on the concept of a sortal property, see Grandy (2014).
} 
(which is what pure sortals give us); they also import other predications, notably those in the category of quality.

This pure/impure distinction also underlies two very important related distinctions, namely that between essential and accidental qualities, as traditionally conceived, and that between qualitative and substantial changes. Humanity is an example of an essential quality, in that if a human ceases to be human, then he or she ceases to exist altogether (pace Ovid, Kafka, et al.). Masculinity, by contrast, is not, for 'There is no longer a man' does not entail 'The man no longer is', as the example of gender reassignment shows. To put it another way, gender reassignment is an example of a qualitative change, i.e. one where the continuant survives the change. By contrast, death is a substantial change, i.e. the sort of change where a continuant either comes into existence or goes out of existence.

The essential/accidental distinction is, I think, a modal distinction, ${ }^{10}$ and we must ask what sort of modality we are dealing with. When I say that I am essentially human, I am assigning a modal property to myself, so we are evidently dealing with a de re modality, the third grade of modal involvement. In short, we have moved into controversial territory, and are invoking a kind of Aristotelian essentialism which was, at least until recently, generally regarded with disfavour. We must therefore ask what legitimizes this essentialism and where it comes from. On my view, modal and temporal contexts are closely related, and in so far as one may quantify into a temporal context, one may explain what it is to quantify into a modal context. Following Dummett (1973: pp. 130-131), one may, indeed, define essential qualities in temporal terms: a property is said to be 'presently essential' to an object if it is true of objects of that sort that it cannot lose this property without ceasing to exist; and it is 'absolutely essential' if it has always been presently essential to it. ${ }^{11}$ A nontrivial definition of some kind is surely needed, given that the idea of essence needs to be fleshed out if it is have a genuine application.

But do the essential/accidental and pure/impure distinctions really coincide? The thesis that they do has an impressive historical pedigree, but more recently has been criticized, for example by Mackie (1994, 2006). It is perhaps not all that obvious that Aristotle was essentially a human being, for example. True, once a human being, always a human being, but why did he have to be human in the first place? Mackie (1994: p. 333) insists that no good reason can be given: or indeed, for why he could not instead have been a centipede, a parsnip, a paperclip —or the number 17 , for that matter. But suppose we grant that if we abandon a sortal-based essentialism then we end up with an extreme minimalism; is not this revised notion of essence so thin as

\footnotetext{
10 Though this is not beyond dispute. Fine (1994) has famously argued that essence cannot be analysed in terms of modality. The matter is discussed also by Correia (2011) and Wildman (2013). For a general survey of these issues, see Robertson and Atkins (2013). These debates are outside the scope of this paper, however, and I shall simply assume a modalist understanding of essence.

11 Assume that the object has the relevant property at some time. This definition will not help us with individualized essences (e.g. that I essentially derive from the particular sperm and ovum that I did), an idea on which (following Wiggins) I have nothing to say. We should likewise ignore the fact that Dummett's definition, as it stands, trivially implies a very strong and implausible version of origin essentialism (I am grateful to a Synthese referee for pointing this out). The definition should be restricted to intrinsic, nonrelational properties. This has its drawbacks, if only because of the difficulty in defining the relational/nonrelational distinction, but I shall assume a basic understanding here.
} 
to be virtually meaningless? Our task, it will be recalled, is to convince the empiricist that a nontrivial conception of an essential property can be legitimated. Even if this conception is somewhat archaic, this would still be a solid achievement; and if the alternative is trivial, then it is evidently less attractive, since it is less in accordance with ordinary usage. After all, that there are no nontrivial essential qualities is more or less what empiricists such as Ayer thought in the first place! I think, therefore, that Mackie's highly sceptical scenario does not undermine my project significantly, since there is at least a fairly plausible remaining conception of the essential/accidental distinction that serves its purpose.

We thus have a working definition, but it is still unclear just how much it helps us. We may have defined modal properties - or a limited set of them-in terms of persistence-conditions, but we still need to ask what underlies the distinction between qualitative and substantial changes, and how we can tell which type of change we are dealing with. This seems to involve necessary a posteriori truths of a kind which a classical empiricist would disavow.

A way forward is to re-examine the possibility of having unusual continuants. I considered the case of a nonstandard continuant that temporarily occupied my bodyspace, but there are more natural examples as well. Wiggins, for example, is concerned with the relationship between a human being and a human body. ${ }^{12}$ The focus of the question is whether ordinary death really is a substantial change after all, given that the body will usually continue to exist for a while afterwards until it decays. How do we decide? Wiggins's (1980: p. 164) view, which I endorse, seems to be that we have here two continuants, the human being and the body, which occupy the same space for some of the time: and death is a substantial change for the former but a qualitative change for the latter. ${ }^{13}$ This is an a priori truth, which can be determined simply by conceptual analysis of the terms 'human being' and 'human body'. We do not need to examine empirically the causal mechanisms of death to see which sort of change we have. The simple fact is that we have both changes, and one potentially difficult empirical decision is thus neatly fragmented into two easy a priori ones.

It may be feared that the pure/impure distinction itself presupposes the legitimacy of essentialist notions, but this is not so. The sortal $f$ is a pure sortal iff it is necessary that, for all $x$, if $x$ is an $\mathrm{f}$ at one time then $x$ is an $\mathrm{f}$ at all times (at which it exists). Here we need to quantify into a temporal context, but not into the modal context. ${ }^{14}$ Likewise, the reason for distinguishing human beings from human bodies arises because it is possible for there to be bodies without concomitant human beings. This only involves the de dicto modal statement 'It is possible that there is a corpse', and does not presuppose any de re modality or essentialist judgements.

That two distinct continuants may be constituted by the same matter at the same time (via different sortals) is a consequence of the doctrine that Wiggins calls 'con-

\footnotetext{
12 He in fact uses the term 'person' rather than 'human being', but the difference is unimportant here.

13 A similar point applies to the familiar example of the statue and the lump of clay from which it is made. I think I have represented Wiggins correctly, but his writing at this point is rather hard to follow, and the two-continuant view is not made explicit.

14 It might be protested that this definition is illegitimate since we have yet to determine the domain of quantification; but it should be noted that matters will not improve merely by introducing further modal operators.
} 
ceptualism' (roughly, the view that objects are conceptual constructions of a certain kind). ${ }^{15}$ It is false, on this account, to claim that two objects cannot occupy the same place at the same time, but it remains (usually) true that two objects of the same sort cannot do so. ${ }^{16}$ The need for sortals thus becomes acute, though we have already seen that they play a vital role. We have noticed how the trick of treating human beings and their bodies as distinct continuants helps to eliminate the need to assume at the outset that there are necessary a posteriori truths, but we still need to show how to deal with other examples. My suggestion is that we generalize this technique, indeed take it to extremes. On my 'radical conceptualist' view, we may work this human/body trick on all changes, by introducing new and unusual continuants. ${ }^{17}$ Thus consider the sortal child. Ordinarily, we suppose this to be an impure sortal (it is an example of what Wiggins calls a 'phased sortal'), since adolescence is not a lethal process: 'There is no longer a child' does not entail 'The child no longer exists' (not in my sense, anyway). But suppose we introduce a new sortal, $P$-child which $i$ s a pure sortal. Wherever we have a child we have a P-child, and wherever we have the same child we have the same P-child. But P-children cannot survive adolescence: for them, it is a substantial change. It follows that no child is ever a P-child, even if the child dies young (they have different modal properties, in a sense that our analysis is here to explicate). Thus $P$-child relates to child rather as human being relates to living human body. Likewise, suppose we take an example of a substantial change, such as Lot's wife's replacement by a pillar of salt. We then introduce a new sortal P-human-pillar for whose compliants crystallization is a qualitative change. Thus every qualitative change is also a substantial change and vice versa, depending on which continuant we look at. This demystifies the distinction, and enables us to at least begin to analyse the essential/accidental distinction in a way that is acceptable to classical empiricists.

It may be protested that this manoeuvre is absurd, since it appears to follow that it is entirely a matter of arbitrary convention whether or not a continuant goes out of existence. As Brody (1980: p. 73) drily asks, if this is so, then why did we not secure our immortality some time ago? But radical conceptualism has no such implications. Any change can be regarded as either qualitative or substantial depending on which continuant we look at, but it in no way follows that once we have specified the continuant we may then go on and decide arbitrarily which sort of change it undergoes. The introduction of the sortal P-human-pillar in no way enables a human being to become a pillar of salt. The only entities that do have this ability are P-human-pillars, weird entities quite different from either human beings or pillars that we are not usually interested in in the first place. Wiggins adopts this line of defence against critics such as Ayers (1974), and argues for the perfect consonance between a sober conceptualism and realism (i.e. the doctrine that continuants come into existence, continue

\footnotetext{
15 For a more recent defence of the distinctness of an object from its matter, which is closely related to conceptualism, see Fine (2003).

16 There are perhaps exceptions. Wiggins (1980: p. 73) cites the example of the Pope's crown which is made of crowns, and also notes that waves may exactly overlap. Quantum entanglement cases also seems to involve problems of this nature. I am grateful to a Synthese referee who drew these facts to my attention. Such exceptions, at least in the macroscopic world, are rare, however, so I do not think that they present my general thesis with any significant problems.
}

17 I first introduce this technique in Unwin (1984), along with many of the related ideas in this section. 
in existence and then go out of existence quite independently of how we think about them). However, he rejects the wilder possibilities and insists on strong constraints on just what can count as a substance concept (Wiggins 1980: pp. 138-140). Now, there may well be good reasons for wanting to reject the more severely eccentric sortals, but the need to avoid unrestricted Protean change is not one of them. The above line of defence, pace Wiggins, works just as well with radical conceptualism as with its more sober cousin, as we have just seen. The introduction of exotic new continuants in no way affects the interesting properties of the original continuants. ${ }^{18}$

Still, it may be felt that we have far too many entities in our ontology. To begin with, not only is it possible to have two continuants occupying the same place at the same time; we can, on my view, have two continuants occupying the same place at all times. For if my body is destroyed at the same moment as my death, my body and I will have the same spatiotemporal spread. It might be thought that in such a case, my body and I will be the same after all, and that overall spatiotemporal coincidence is a perfectly serviceable identity criterion for continuants, but this is implausible. At this moment, it is undetermined whether my body and I will go out of existence at the same time: if I die by the bullet, they won't; and if I die by the bomb, they will. If we adopt the premise for which I have no argument but which seems plausible enough, namely that if A and B completely and determinately exist here and now then the question of whether they are the same or different must depend only on facts that completely and determinately obtain here and now (and not, for example, on any future contingencies), then I must suppose that my body and I are definitely different, and will remain so regardless of how I actually come to die. As with the child and the P-child, they have different modal properties in a sense that is now a little clearer.

In fact, we can take things further. If we allow peculiar sortals, we can ensure that any connected spatiotemporal region occupied by matter forms the spread of a continuant. Indeed, since given any sortal $f$, we may construct the artificial sortal $P-f$-which-is- $\varphi$, for any nonrelational property $\varphi$ which a given $\mathrm{f}$ happens to have throughout its existence, it follows that any such region forms the spread of a nondenumerable infinity of continuants, or as many continuants as there are admissible properties $\varphi$. This is about as generous an ontology as one can get! It is an extreme generalization of an Aristotelian hylomorphism where each substance, or continuant, is a compound of form (pure sortal) and matter. It differs from Aristotle's version primarily in that there are vastly more properties that may constitute 'forms' in the relevant sense.

Is such extremism desirable? It should be noted that it provides a solution to the central problem of why some of a given object's properties are modalized and others

\footnotetext{
18 It might still be felt that Brody has a point with regard to the issue of personal identity. On my view, there are an infinite number of continuants sitting here in this chair. Which one am $I$ ? The question is of considerable importance, if only to me, but there seems to be no obvious way of answering it (I am grateful to a Synthese referee for pointing this out). However, the distinction between normal and abnormal substances, which will be discussed later in this paper, provides the key. My body and I (the person) are the only normal substances sitting in this chair. It might be further objected that, for all I know, I am not a normal substance after all. I am unable to rule this out conclusively, but there does not seem to be any positive reason for thinking so, and sceptics should bear at least most of the burden of proof when their hypotheses are contrary to common sense. Notice also that even if I did survive bodily death, I would not continue to have consciousness, so there is no practical advantage involved.
} 
not. The point is that for each combination of modalized and unmodalized properties, there is an object which has them. As Bennett (2004: p. 355) puts it:

If only some of the possible modal profiles are instantiated in a region, we can always ask why those are so special - which ... is just to ask why the things that exist there have the modal properties they do. An answer of 'they just do' sounds decidedly mysterious and obfuscatory. But if all of the possible modal profiles are instantiated, the question simply does not arise. Thus the fullness of each spatiotemporal region explains - or at least explains away - the primitiveness of the de re modal facts.

This superabundantism, or 'plenitudinous primitivism' as Bennett calls it, clearly has serious advantages. My approach goes further in so far as the superabundantism is used to explain the very notion of a modal property itself, and this gives us yet more advantages.

It may be still be protested that, so construed, continuants have identity criteria that are far too fine-grained. Indeed, continuants are as finely grained as sortal concepts themselves, individuated at least up to logical equivalence. This is odd if only because concepts and propositions have parallel identity criteria (they are also individuated up to logical equivalence, or even more finely), and it may be insisted that continuants are not remotely like propositions so individuated. It is worth noting, however, that if we are able to get away with denying this, we can start to see quite clearly why many modalities de re are reducible to modalities de dicto. The amazing fact is that there is surprisingly little difference between a res and a dictum!

This may seem a quite intolerable idea, but it is important to see that it is highly misleading to suppose that what is intuitively objectionable about my radical conceptualism is that continuants, so construed, have very finely-grained identity criteria. We do not have the situation where we both agree that entities A and B exist, but where I say they are not identical and you say they are. The situation, rather, is that the existence of at least one of A and B is typically rejected in the first place. In short, the complaint is that there are, quite literally, too many continuants on my view. The situation is therefore to be rectified not by fusion (coarsening the identity criteria) but by exclusion (ontological pruning). Yet even if we were to undertake drastic pruning, the residual entities will still be, in a sense, very finely grained entities, so the parallel between res and dictum remains unaffected. ${ }^{19}$

The natural view, however, is that such pruning is unnecessary because the exotic continuants should never have been admitted in the first place. Yet we have seen how such exotica can have a useful philosophical purpose when it comes to trying to demystify de re modality, so we need to inquire more carefully if they really exist or not. How can we tell? It is always hard to determine such matters, as can be seen by examining other sorts of entity. Consider, in the first instance, sets. Do sets whose

\footnotetext{
19 This might be disputed on the grounds that P-f-which-are- $\varphi$ s, for detailed $\varphi$, are more finely grained than are P-f-which-are- $\varphi s$, for undetailed $\varphi s$. In a sense, perhaps, they are; but not in the sense that is relevant here. In my sense, sortal properties_-indeed, all properties, detailed or otherwise — are equally finely grained (as mentioned, they are identified at least up to logical equivalence). The same should therefore apply to their compliants with or without pruning, given that the P-f-which-is- $\varphi$ at region $X=$ the P-f-which-is- $\psi$ at region $\mathrm{X}$ only if $\varphi=\psi$.
} 
elements are absurdly disparate really exist: for example, the set whose elements are London, Mount Everest and my left ear? Such a set is certainly useless for normal purposes, but most people would not want to rule it out of existence altogether. It is just too difficult to figure out how.

What about properties? Does Goodman's infamous predicate 'grue' denote a real property? It surely depends a bit on the context. The same applies to the putative property of being either London, Mount Everest or my left ear. With regard to actual physical objects, there is a well known debate over whether arbitrary mereological sums are permissible, such as the sum of (once again) London, Mount Everest and my left ear. ${ }^{20}$ It may be thought that such absurdities should definitely be excluded, but it may also be felt that such odd composite entities, like the odd sets, are harmless, and that it is too much trouble trying to find principled ways of excluding exactly what needs to be excluded.

To be sure, in all these cases, we can and need to make some sort of distinction between a normal and an abnormal example of an entity of the appropriate type in order to determine a reasonable domain of quantification, one which is usable for practical purposes. But notice once again that just how we draw such distinctions is usually going to depend very much on context. For some purposes, my suitcase with all its contents, or my cat minus its tail, count as independent, single objects in their own right; for others, they do not. Yet if we adopt an austere ontology, and declare that the odd entities do not exist at all, we lose the contextualism and introduce a kind of ruthless streamlining that does not really do justice to the complexity of the subject matter. It is surely better to start off with a generous ontology which avoids elaborate principles of exclusion; and then take it from there.

It may still be felt that continuants, so construed, are too much like logical artefacts to have the fundamental role they seem to have in our metaphysics. Following Strawson (1959), we might not unreasonably declare that continuants are the 'basic particulars', that is to say, particulars which do not need to be identified and reidentified via other types of particular, such as events or processes. This gives them a fundamental quality. However, this involves an epistemological rather than a metaphysical conception of what is basic. It concerns how we ourselves are oriented within the world, rather than the fundamental nature of the world itself. A view which I find attractive, though shall not defend in any detail (however, see Sect. 5 below), is that the metaphysically fundamental elements of reality - all that ultimately exist-are four-dimensional chunks of stuff, individuated up to spatiotemporal coincidence: in short, processes rather than continuants. This gives us a nice, simple ontology of worldly, very coarsely grained entities on which other sorts of entity supervene. Continuants, by contrast, are logical constructions out of such four-dimensional chunks, and are arrived at by a process

20 See, for example, Simons (1987). 
of abstraction. ${ }^{21}$ Given their metaphysically non-basic status, the sheer number of continuants (on my view) is less of a problem than it might otherwise be. ${ }^{22}$

Nevertheless, in order to return to anything like our ordinary system, we do need to provide criteria of normality so as to exclude the exotic substances, if only to satisfy ourselves that the target essential/accidental distinction does not need to be smuggled back in in an unanalysed form. Wiggins (1980: p. 70) claims that, in order to qualify as a genuine substance, the continuant needs to have a distinctive activity, function or purpose, and this gives us the beginnings of what we are looking for. We can see why adolescence is typically regarded as a qualitative and not a substantial change because of the general continuity involved in the transition from child to adult. This is why $P$-child is an abnormal sortal, and its compliants abnormal continuants. The transition from Lot's wife to a pillar of salt, by contrast, involves very significant discontinuities, which would lead us to suppose that the change is substantial, and that P-humanpillar is therefore an abnormal sortal, and its compliants abnormal continuants. Insect metamorphosis can be handled in a similar way, though the qualitative change from caterpillar to butterfly is more complex and dramatic, as can the substantial change involved in the superficially similar process whereby an ichneumon wasp emerges from a parasitized pupa (the difference is in the nature of the underlying causal mechanisms). There are huge issues here, of course, but the details need not concern us. What is crucial is that the normal/abnormal distinction is quite different from the pure/impure distinction, and the questions 'What makes a normal sortal normal?' and 'What makes a pure sortal pure?' need quite different sorts of answers. The latter is simply a matter of a priori conceptual analysis; the former involves attention to empirical detail.

This is why my two-stage treatment is more helpful than Wiggins's account. By firstly allowing abnormal pure sortals, we ensure that nothing beyond analyticity is actually needed to formulate the essential/accidental distinction. After we have done that, we then-but only then-introduce the normal/abnormal distinction (the second stage of the analysis), and thus bring things back (approximately) to where they were originally. This saves us from having to take abnormal continuants too seriously. My 'radical conceptualism' is thus rendered completely harmless, though still useful.

It may be protested that all this is to ignore the special role of natural kinds in determining the essential/accidental distinction, given that determining whether a type of entity forms a natural kind is typically an empirical issue. This is related to an important objection from Ayers (1974) that, according to Wiggins, we (apparently) cannot refer successfully to an individual unless we firstly know what it essentially is. This problem becomes particularly acute with my radical revision of Wiggins given the number of alternative candidates for reference on offer. This seems wrong. I can successfully refer to a tadpole without knowing that it is an immature frog: that tadpoles turn (qualitatively, not substantially) into frogs is not something we decided; we learnt

\footnotetext{
21 On this, see also Simons (2000). The standard debate as to whether objects are three or four dimensional is thus sidestepped: on my view (and, I think, Simons'), there are both kinds of entity. Merricks (1995) argues that this is impossible, but his argument hinges on different theories about time which lie beyond the scope of this paper.

22 This is perhaps to assume that non-fundamentalia require less critical attention than do fundamentalia, a meta-ontological thesis that could be disputed. However, I shall not attempt to adjudicate any such dispute here.
} 
it. It seems then that the necessary and the a posteriori have not been disentangled in the way that I require.

But this objection can be answered if we adopt the broad picture presented by Kripke and Putnam as to how natural kind terms get their meaning, perhaps adjusted in accordance with the more recent two-dimensionalist account mentioned in Sect. 2. The term 'tadpole', for example, is not defined in a Lockean sort of way, by means of its 'nominal essence' or set of ideas that we naturally associate with the term. If we did that, then tadpoles and frogs would indeed constitute different species. Instead, we define a tadpole as anything with the same internal constitution as this (ostensively identified) entity. Given the many alternative candidates for reference here, we may qualify this by insisting that by 'entity' here we mean 'normal continuant'. Let us hope that there is only one of them here (if there is not, then there will be problems, but not specifically mine). We may then discover empirically what this internal constitution is, and what features are really relevant (obviously, not all nonrelational features). We do not know in advance what these features are going to be, but we do know in advance what our canons of relevance are. We may then perform a parallel investigation with an adult frog, and hence learn that tadpoles are immature frogs. ${ }^{23}$ The only conception of necessity that we have to assume at the outset is that of analyticity. It is just that empirical investigation is often needed to determine just which concepts need to be analysed, namely those normal sortal concepts which happen, as a matter of contingent fact, to be instantiated at given ostensively identified places and times. ${ }^{24}$

Thus, although we may have necessary a posteriori truths, the necessity resides in a priori facts and the a posteriori quality resides in contingent facts. The combination between necessity and the a posteriori is rendered superficial, and comes apart upon analysis. Now, this is also what the two dimensionalists say, so how does this more modern debate relate to the earlier one? The former employs a distinction between primary and secondary intensions, (which gives us the 'two' in 'two-dimensionalism'), and the focus is on the relationships between possible worlds, which are arranged in a matrix structure. The more technical details need not concern us, but the standard example of a necessary a posteriori truth is 'Water is $\mathrm{H}_{2} \mathrm{O}$ ', rather than (anything like) 'Tadpoles are immature frogs'. However, the notion of ostensive location, or (more generally) indexicality, is common to both types of example. Indeed, twodimensionalism was originally devised as a theory to handle the semantics of sentences that contain indexicals (such as 'I am here now'), and was generalized largely because indexicality plays such a central role in the Kripke-Putnam account of natural kinds (or of a central way of reading it). Thus ' $\mathrm{X}$ is water' is held to be true just in case $\mathrm{X}$ has the same (possibly unknown) internal constitution as this (ostensively identified) stuff. This is the necessary part, which is also a priori. We then go on and find out that the stuff occupying our ostensively identified place and time is $\mathrm{H}_{2} \mathrm{O}$, and this is the a

\footnotetext{
23 This is not to say that mature frogs have exactly the same internal constitution as tadpoles. Rather, it is to say that a basic similarity of constitution, perhaps at a very deep level, together with factors such as continuity, yield identity. Such matters are more complex and delicate than are often thought, and much devil is in the detail; but they do not seem to presuppose a grasp of the target essential/accidental distinction, which is all that really matters here. On this, see also Unwin (1996a).

24 That the a posteriori elements of necessary a posteriori truths emanate from contingent facts is also argued for by Jackson (2010), though in a slightly different way. See also Mackie (2010).
} 
posteriori part, which is also contingent (some quite different 'watery stuff', such as Putnam's XYZ, might have been situated there instead). This yields 'Water is $\mathrm{H}_{2} \mathrm{O}$ ' as a necessary a posteriori truth, but (when properly analysed) a harmless one.

So much is familiar. Yet there remains a difficulty when we remember that portions of water, like tadpoles, are continuants, and that the areas of space and time that we use to identify them ostensively are unlikely to be their entire spatiotemporal spreads. Something more is therefore needed to ensure effective reference. This additional element, which forms the core of the neo-Aristotelian approach presented by Wiggins and myself, involves an analysis of the essential/accidental distinction that is missing from two-dimensionalism. ${ }^{25}$ This is significant, since this more modern approach presents itself as giving an analysis of the semantics of modal logic, and therefore should encompass the modal distinction between the essential and the accidental. That it does not quite do this unless it is supported by something like the neo-Aristotelian account shows that the earlier and the more recent debates are more closely connected than they might appear to be.

\section{The Wiggins-Ayer debate}

In Macdonald (1979: pp. 131-160 and 306-314), Wiggins and Ayer resume their longstanding discussion about whether there are such things as essential properties. Ayer maintains, as mentioned above, that necessity is nothing over and above analyticity, from which it follows that the truth value of 'A is necessarily $\varphi$ ' is going to depend on how $\mathrm{A}$ is described. This is because it may be that ' $\mathrm{A}$ is $\varphi$ ' is analytic, ' $\mathrm{B}$ is $\varphi$ ' is synthetic, and yet $\mathrm{A}=\mathrm{B} .{ }^{26}$ The thought that $\mathrm{A}$ as such might have $\varphi$ as an 'internal property', or that $\varphi$ might be part of the individual essence of A (in some sense), is just rejected as meaningless. Wiggins, by contrast, defends a weak doctrine of essentialism that draws on Leibniz (of the Nouveaux Essais) as well as Aristotle. Much of the debate revolves around Ayer's example, 'My newspaper necessarily contains news', which he maintains is uninterestingly true, but only because it involves nothing much more than the fact that 'My newspaper does not contain news' is self-contradictory. Wiggins maintains that more can be said here, but not a great deal if only because newspapers are artefacts, not natural kinds, and therefore lacking in interesting essential properties. He does, however, suppose (I think) that containing news is an essential property of newspapers. The debate is complicated by the use of the singular term 'my newspaper', since apart from the existence condition (which also undermines the analyticity of 'A is $\varphi$ ', mentioned above), it involves complex issues about the semantics of proper names and definite descriptions which are not directly relevant. It would be better, I think, if instead we consider the sentence

\footnotetext{
25 The issue is complicated by the fact that portions of stuff, unlike individual objects, seem to involve a kind of mereological essentialism. They contain all their parts essentially, and this fact seems to play a greater role in their identity criteria than do continuity-conditions. However, they can undergo certain sorts of change (e.g. heating), but not others (e.g. certain chemical changes), and so need to be sensitive to many of the issues that we have been considering.

26 For example (Ayer's), let 'A' be 'the author of Hamlet', 'B' be 'the author of Macbeth', and ' $\varphi$ ' be 'the author of Hamlet'.
} 


\section{(1) All newspapers are necessarily newspapers}

which involves no singular terms. Now, in QML, this sentence can be translated in two different ways and the difference hinges on a scope distinction. Specifically, we have:

(2) $\square \forall x(N x \rightarrow N x)$

and

(3) $\forall x(N x \rightarrow \square N x)^{27}$

where ' $N x$ ' means ' $x$ is a newspaper'. (2) is simply a theorem of QML, and gives us the trivial de dicto reading of (1), the one that Ayer accepts. (3), by contrast, involves quantifying into the modal context, and thus gives us the more controversial de re reading. Although it contains no singular terms, it says that, given any newspaper, that entity-regardless of how we choose to describe it-is necessarily a newspaper, or has the property of being-a-newspaper essentially, if you prefer. This is the reading that Ayer regards as meaningless, and Wiggins believes (I think) to be true though uninterestingly so. My intuition, however, is that (3) is actually false, because newspaper is not, in my opinion, a pure sortal. Specifically, suppose that my newspaper were to lose all its newsprint whilst remaining folded (perhaps it was printed using disappearing ink). Would it continue to be a newspaper? I think not. But would it continue to exist? I think so. The change is surely qualitative, not substantial: that newspaper-that organized collection of sheets of paper-still exists, but is just no longer a newspaper. If this is right, then it would certainly reinforce the claim that (2) and (3) are quite different readings since they have different truth-values.

But in any event, there are plenty of other interpretations of ' $N x$ ' for which (3) is definitely false. The sentence 'All teachers are necessarily teachers' is one, since teacher is certainly not a pure sortal. The same can be said of 'All criminals are necessarily criminals', for which the (3) reading suggests criminal predetermination of a highly implausible kind. This is not an invariable rule, however, for 'All human beings are necessarily human beings' has, I think, no false reading. The difference is that human being is a pure sortal: although leaving the teaching profession or a life of crime is not lethal, leaving the human race is. There therefore is an interesting distinction here, and it hinges precisely on whether we are dealing with pure sortals or not, which in turn depends on the persistence conditions of continuants, as argued above.

So should Ayer accept this? Specifically, should he accept certain de re necessities whilst remaining sceptical of any conception of necessity other than analyticity, or at least which cannot be generated from analyticity? My thesis is that he should: a limited version of essentialism has been defanged, and many ordinary de re locutions can be understood in their own terms and legitimized within an epistemologically very austere empiricist framework. The property of necessarily-containing-news is not unduly mysterious after all, and we do not need to penetrate beyond surface appearances in a manner that Hume thought impossible to determine that my newspaper does not have

\footnotetext{
27 To work appropriately, the modal operator has to represent weak necessity, i.e. truth in all possible worlds in which the relevant object exists at all. An alternative rendering is ' $\forall x(N x \rightarrow \square(x$ exists $\rightarrow N x))$ '.
} 
it. Any act of observing a newspaper is indistinguishable from the act of observing a P-newspaper or a P-newspaper-which-is- $\varphi$, for any property $\varphi$ which the newspaper happens to have. The latter entities do necessarily contain news, even though the former does not, but it is conceptual analysis rather than empirical (or super-empirical) observation which enables us to know this.

There are some questionable assumptions here, to be sure. Some might say that losing newsprint is a substantial change for a newspaper after all, or possibly that a newspaper which has lost its newsprint is still technically a newspaper: in both these cases, newspaper might qualify as a pure sortal, in which case (3) becomes true. Likewise (to consider a different possibility), we might argue over whether the newspaper can survive a separation of its pages (bearing in mind that they could always be recombined later), and other changes are also debatable. But all this shows is that, where a term such as 'newspaper' is well entrenched in the language (as 'Pnewspaper', for example, is not), its analytic connections may be hard to pin down. Natural languages are, after all, complex things. Matters get yet more complex still when we consider natural kind terms, but the same point applies: any act of observing a tadpole, for example, is indistinguishable from observing a P-tadpole-which-is- $\varphi$. The analytic/synthetic distinction was never that straightforward to begin with, so we can certainly expect many examples to be controversial to some degree. What is important is that the necessary and the a posteriori can be successfully separated, at least in a wide variety of cases.

How far does this extend? Standard examples of necessary a posteriori truths include identity statements such as 'Hesperus is Phosphorus'. This can be handled by noting that the property of being-identical-to-Phosphorus is absolutely essential to Hesperus according to our definition. We thus do not need to talk here of rigid designation or trans-world identity, concepts whose legitimacy presupposes rather a lot (as was noted in Sect. 2). The sentence 'Water is $\mathrm{H}_{2} \mathrm{O}$ ' is less easily handled because 'water' is a mass noun, not a count noun. But portions of water are still continuants of a sort (as we noted earlier), and we need criteria that determine whether they survive certain types of change such as boiling, electrolytic separation into hydrogen and oxygen components, and so on. Likewise, the fact that 'Gold has atomic number 79' is necessary, whereas 'Gold is yellow' is contingent, can also be handled in an analogous way. We are perhaps less sure how the qualitative/substantial change distinction applies in such cases, but then I think we are equally less sure about the relevant modal claims, so it is unclear if this matters very much. The point is that we can see what is going on, and why the relevant modal claims are true, if and when they are true, something which two-dimensionalism does not obviously do (but should do, if it is to be fit for purpose). This is why the Wiggins-Ayer debate is still relevant to current concerns.

\section{Non-continuants and non-essentialism}

Still, some will say that there was never much of a problem in the first place. I suggest, however, that there was and is, and the point is that it is very hard to extend a non-trivial essential/accidental distinction to non-continuants, entities where we cannot use the above analysis; and furthermore that this is not because of doubts as to 
whether such entities really exist. I mentioned earlier that, in my unargued opinion, the metaphysically most basic entities are not continuants themselves (pace Strawson), but four-dimensional 'chunks' of stuff (for want of a better word) individuated up to spatiotemporal coincidence. Their simple and very coarsely-grained identity criteria are themselves a sign of some kind of ultimate worldliness. They are not continuants, but do their properties admit of the distinction between the essential and the accidental? The trouble is that we do not have the faintest idea of what could underlie the distinction. Consider, for example, what we may call hypothesis H1. According to H1, chunks have all their properties essentially, including their spatiotemporal locations: this particular chunk could not have 'moved' differently from the way it did. Is this plausible? It sits oddly with the essential/accidental distinction as applied to the continuants that could be constructed from it, but this is not decisive. It means a very close connection between such pieces of stuff and the spatiotemporal regions that they occupy, a view which has a Cartesian ring to it. It perhaps involves a conception of absolute space (and time), but we should not worry too much about that (physicists nowadays are less sceptical about the notion than they used to be). This gives us a maximal version of essentialism.

Consider now hypothesis H2. This makes all the nonrelational properties essential, but not the spatiotemporal location. Such portions of stuff can 'move' without ceasing to exist, but they cannot otherwise vary. This is less than maximal. It would be nice to find an even weaker hypothesis $\mathrm{H} 3$, one which more closely resembles the essential/accidental distinction as applied to continuants, but here we reach a problem. As mentioned, on my account, any spatiotemporal region occupied by matter forms the spread of nondenumerably many continuants, each with different essential properties, and this yields a massive indeterminacy. True, we could eliminate most of them by ignoring the abnormal continuants, but even this will not really give us what we want, for this proposed criterion concerns only the possible ways that a chunk can vary along its temporal dimension. What we want to know is in what ways we could vary that whole chunk and yet it remain the same chunk. No obvious answer springs to mind.

Of course, we could always stipulate various things, including the most minimal hypothesis $\mathrm{H} 4$, namely that all nontrivial properties of chunks are accidental, but the point is that such stipulations are purely idle, as are such stipulations with respect to continuants (pace Mackie: see Sect. 3 above). It is, of course, no use merely invoking QML with possible world domains consisting primarily of chunks. The mathematics will be there in place, but it has no determinate application. The essential/accidental distinction has no authentic role to play when it comes to chunks. True, this need not be forever so. It remains open for someone to come up with a principled way of applying the distinction, one which serves some legitimate purpose, and I cannot rule out this possibility. But the point is that, unless and until we have such additional features in place, all the hypotheses considered are equally vacuous. It is not just that such hypotheses are unknowable: rather, there is simply nothing to know. They involve metaphysical speculation in the very worst sense of the word. I do not wish to say that such claims are actually meaningless, or even that they are not truth-apt. It is just that we can have two theories $\mathrm{T}_{1}$ and $\mathrm{T}_{2}$ which assign mutually incompatible modal properties to chunks: and yet there is just no fact of the matter as to which theory is true. Debate is therefore pointless. 
Moreover, the two-dimensionalist approach will not separate the necessary and the a posteriori elements in any way which would alleviate the problem. A distinction between primary and secondary intensions might help to elucidate the a posteriori necessity involved with 'Water is $\mathrm{H}_{2} \mathrm{O}$ ', or 'Aristotle is a human being', but it can do nothing for four-dimensional chunks. This is because what we need are intuitions that could enable us to determine which properties of raw four-dimensional chunks should be modalized and which should not, and we do not have any. Such intuitions are going to be needed before we can initiate the two-dimensional apparatus and determine whether or not chunk A has property B in possible world C. Since two-dimensionalism does not specifically mention the kind of ontologies that it can work for, this points to a defect within it if it is understood to give a wholly general account of how the necessary and the a posteriori are to be disentangled in all contexts.

Admittedly, chunks are rather unfamiliar entities, but a similar point applies to events as ordinarily understood. Most people (pace Quine 1950) feel that the heating of a metal ball at time $t$ is a different event from its rotation at $t$, even though they are spatiotemporally coincident; but they also feel (pace Kim 1976) that Sebastian's walk at $t$ is the same event as his slow walk at $t$ even though walks and walks slowly are different constitutive properties. The identity criterion for events thus seems to be midway in stringency between spatiotemporal coincidence and logical equivalence (of constitutive properties), but we cannot agree on what such an intermediate criterion is. ${ }^{28}$ A natural suggestion is that we adopt a criterion similar to that for continuants and place events under sortal concepts, of which there are many (heating, rotation, walk, slow walk, birthday party, celebration, theatrical performance, theatrical performance of Lulu in Chicago, shooting, assassination, and so on). A single event may fall under more than one sortal concept (a birthday party can be a celebration, and so on), just as a single continuant can, so we are not forced into Kim's excessively fine-grained position. And if distinct substances can be spatiotemporally coincident (via different sortals), then so can distinct events, so we are not forced into Quine's excessively coarse-grained position either. The trouble, however, is that we lack a distinction here between pure and impure sortals. We thus cannot tell whether the instantiations of two event-sortals $f$ and $g$ at the same spatiotemporal zone constitute the same event-token, for we do not know if there is some one pure sortal of which $f$ and $g$ are restrictions. Similarly, we cannot tell how to distinguish essential from accidental qualities. Should we say of the assassination of JFK that it was essentially an assassination? Perhaps not, for JFK might have survived the shooting, and the shooting is arguably the same event as the assassination (to take a well known controversial example). But was the shooting essentially a shooting? The trouble is not just that we do not know: we do not even know how to find out! We likewise do not know whether heatings are essentially heatings, or whether rotations are essentially rotations, and so on. There seems to be nothing analogous to persistence through time that could ground the essential/accidental distinction, so the speculation is simply idle. Of course, we may simply conclude that events are nonexistent entities, since systematic identity criteria are missing and there can be 'no entity without identity', as Quine puts it. But, as noted above, the same point (about idle speculation) applies

28 This issue is developed in more detail in Unwin (1996b). 
to four-dimensional chunks for which spatiotemporal coincidence provides the simplest and most straightforward identity criterion imaginable. The essential/accidental distinction has no obvious place, at least amongst concrete items, outside the realm of changeable continuants. ${ }^{29}$

\section{Conclusion}

A conception of necessity that yields a transparent context, and with it QML itself, has been vindicated. Although this conception evidently differs from analyticity, it can be generated from it in the way shown, provided that we avoid individualized essences and stick to an ontology of continuants. Continuants themselves can be effectively individuated, though in an unexpectedly fine-grained fashion. The Wiggins-Ayer debate was revived, and has now been concluded satisfactorily; and its connection with more recent debates, notably concerning two-dimensionalism, has been established, thus ensuring its contemporary relevance. ${ }^{30}$

Open Access This article is distributed under the terms of the Creative Commons Attribution 4.0 International License (http://creativecommons.org/licenses/by/4.0/), which permits unrestricted use, distribution, and reproduction in any medium, provided you give appropriate credit to the original author(s) and the source, provide a link to the Creative Commons license, and indicate if changes were made.

\section{References}

Ayer, A. J. (1979). Replies. In G. F. Macdonald (Ed.), Perception and identity: Essays presented to A.J. Ayer with his replies to them (pp. 277-333). London: Macmillan.

Ayers, M. (1974). Individuals without sortals. Canadian Journal of Philosophy, 4, 113-148.

Bennett, K. (2004). Spatiotemporal coincidence and the grounding problem. Philosophical Studies, 118, 339-371.

Brody, B. A. (1980). Identity and essence. Princeton: Princeton University Press.

Correia, F. (2011). On the reduction of necessity to essence. Philosophy and Phenomenological Research, 84, 639-653.

Della Rocca, M. (2011). Primitive persistence and the impasse between three-dimensionalism and fourdimensionalism. Journal of Philosophy, 108(11), 591-616.

Dummett, M. (1973). Frege: Philosophy of language. London: Duckworth.

Fine, K. (1994). Essence and modality. Philosophical Perspectives, 8, 1-16.

Fine, K. (2003). The non-identity of a material thing and its matter. Mind, 112, 195-234.

Garcia-Carpintero, M., \& Macia, J. (Eds.). (2006). Two-dimensional semantics: Foundations and applications. Oxford: Oxford University Press.

Grandy, R. E. (2014). Sortals, The Stanford encyclopedia of philosophy (Spring 2014 edition), E. N. Zalta (Ed.). http://plato.stanford.edu/archives/spr2014/entries/sortals/. Accessed Jan 2018.

Hawley, K. (2015). Temporal parts, The Stanford encyclopedia of philosophy (Winter 2015 edition), E. N. Zalta (Ed.). http://plato.stanford.edu/archives/win2015/entries/temporal-parts/. Accessed Jan 2018.

\footnotetext{
29 Perhaps abstract objects have essential and accidental properties. For example (from a Synthese referee) the number two is essentially prime but only accidentally the number of planets closer to the sun than the Earth. However, abstract objects are so different from physical objects, events and chunks that they do not, I think, undermine my point.

30 I am grateful to suggestions made at a meeting of the Lancaster University Philosophy Work in Progress seminar, where an earlier version of this paper was presented. I am also especially grateful to two Synthese referees who made many helpful and detailed comments on several earlier drafts of this paper.
} 
Jackson, F. (2010). Possible worlds and the necessary a posteriori. In B. Hale \& A. Hoffman (Eds.), Modality: Metaphysics, logic and epistemology (pp. 257-266). Oxford: Oxford University Press.

Kim, J. (1976). Events as property exemplifications. In M. Brand \& D. Walton (Eds.), Action theory (pp. 159-177). Dordrecht: Reidel.

Kripke, S. (1980). Naming and necessity. Oxford: Blackwell.

Macdonald, G. F. (Ed.). (1979). Perception and identity: Essays presented to A.J. Ayer with his replies to them. London: Macmillan.

Mackie, P. (1994). Sortal concepts and essential properties. The Philosophical Quarterly, 44, 311-333.

Mackie, P. (2006). How things might have been. Oxford: Oxford University Press.

Mackie, P. (2010). Response to Frank Jackson. In B. Hale \& A. Hoffman (Eds.), Modality: Metaphysics, logic and epistemology (pp. 267-274). Oxford: Oxford University Press.

Merricks, T. (1995). On the incompatibility of enduring and perduring entities. Mind, 104, 523-531.

Putnam, H. (1975). The meaning of "meaning". In H. Putnam (Ed.), Mind, language and reality (pp. 215-271). Cambridge: Cambridge University Press.

Quine, W. V. (1950). Identity, ostension and hypostasis. In From a logical point of view (pp. 65-79). Cambridge, MA: Harvard University Press.

Quine, W. V. (1971). Quantifiers and propositional attitudes. In L. Linsky (Ed.), Reference and modality (pp. 101-111). Oxford: Oxford University Press.

Quine, W. V. (1976). Three grades of modal involvement. In The ways of paradox and other essays (pp. 156-174). Cambridge, MA: Harvard University Press.

Robertson, T., \& Atkins, P. (2013). Essential vs. accidental properties. The Stanford encyclopedia of philosophy (Winter 2013 edition), E. N. Zalta (Ed.). http://plato.stanford.edu/archives/win2013/entries/e ssential-accidental/. Accessed Jan 2018.

Simons, P. (1987). Parts: A study in ontology. Oxford: Oxford University Press.

Simons, P. (2000). Continuants and occurrents. In Proceedings of the Aristotelian Society, supplementary volume (pp. 59-75).

Strawson, P. F. (1959). Individuals. London: Methuen.

Unwin, N. (1984). Substance, essence, and conceptualism. Ratio, 26, 41-53.

Unwin, N. (1996a). Locke on language and real essences: A defense. History of Philosophy Quarterly, 13, $205-219$.

Unwin, N. (1996b). The individuation of events. Mind, 105, 315-330.

Wiggins, D. (1979). Ayer on monism, pluralism and essence. In G. F. Macdonald (Ed.), Perception and identity: Essays presented to A.J. Ayer with his replies to them (pp. 131-160). London: Macmillan.

Wiggins, D. (1980). Sameness and substance. Oxford: Basil Blackwell.

Wiggins, D. (2001). Sameness and substance renewed. Cambridge: Cambridge University Press.

Wildman, N. (2013). Modality, sparsity and essence. Philosophical Quarterly, 63, 760-782.

Williamson, T. (2013). Modal logic as metaphysics. Oxford: Oxford University Press.

Yablo, S. (1987). Identity, necessity and indiscernibility. Journal of Philosophy, 84, 213-314. 